\title{
Competência em informação e os contextos educacional, tecnológico, político e organizacional
}

\author{
Selma Letícia Capinzaiki Ottonicar \\ selma.leticia@hotmail.com \\ Marta Lígia Pomim Valentim \\ valentim@valentim.pro.br \\ Glória Georges Feres \\ gloriaferes@gmail.com \\ Departamento de Ciência da Informação, Faculdade de Filosofia e Ciências, Universidade Estadual Júlio \\ de Mesquita Filho, Marília, SP, Brasil
}

Resumo: Atualmente a competência em informação tem sido estudada em diferentes contextos sociais. Sendo assim um artigo que demonstre as principais atuações desta competência contribui na construção do pensamento complexo do pesquisador e do público em geral. Portanto a presente pesquisa possui a seguinte questão norteadora: como a competência em informação influencia os diferentes contextos sociais? Ressalta-se que foram escolhidos os principais âmbitos de influência a fim de que o leitor possua uma visão amplificada sobre o tema, contudo uma pesquisa que apresente todas as perspectivas de um conhecimento é improvável. Como procedimentos metodológicos o artigo apresenta uma pesquisa exploratória baseada em uma revisão bibliográfica. Nas considerações finais afirma-se que a competência em informação está presente na política, pois é um fator que permite exercer a cidadania; nas escolas desenvolvendo o aprendizado dos estudantes; além disto, é necessária no manuseio das tecnologias e é uma estratégia de vantagem competitiva nas organizações.

Palavras-chave: competência em informação; interdisciplinaridade; pensamento complexo; contextos da competência em informação.

Information literacy and the educational, technological, political and organizational contexts

Abstract: Nowadays Information Literacy is studied in different contexts in society. So an article which demonstrates the main influences of this literacy contributes to the construction of researcher and general pubic complex thought. This paper has the following research problem: how does information literacy influences in the different social contexts? There were chosen the main influence to provide an amplified vision about the subject however; a research that show not all perspectives of a knowledge is possible. As methodological procedures, this article introduces an investigative research based on a literature review. As a final consideration, information literacy is present in policy, since it is a factor that allows exercise of citizenship; it is also present at schools developing students' learning. In addition, it is necessary to use technology and it is a strategy for competitiveness in organizations.

Keywords: information literacy; interdisciplinary; complex thought; information literacy contexts.

La Alfabetización Informacional y los contextos educativo, tecnológico, político y organizacional

Resumen: Actualmente la competencia en información ha sido estudiada en diferentes contextos sociales. Siendo así un artículo que demuestre las principales actividades de esta competencia contribuye en la construcción del pensamiento complejo del investigador y del público en general. Por lo 
tanto la presente investigación posee la siguiente interrogación orientadora: ¿cómo la competencia en información influencia los diferentes contextos sociales? Se resalta que fueron escogidos los principales ámbitos de influencia a fin de que el lector posea una visión amplificada sobre el tema, pero una investigación que presente todas las perspectivas de un conocimiento es difícil. Como procedimientos metodológicos el artículo presenta una investigación exploratoria basada en una revisión bibliográfica. En las consideraciones finales se afirma que la competencia en información está presente en la política, pues es un factor que permite ejercer la ciudadanía; en las escuelas desarrollando el aprendizaje de los estudiantes; además de esto, es necesaria en la manipulación de las tecnologías y es una estrategia de ventaja competitiva en las organizaciones.

Palabras clave: alfabetización informacional; interdisciplinariedad; pensamiento complejo; contextos de alfabetización informacional. 


\section{Introdução}

Diversos autores como Borko (1968), Saracevic (1995), Choo (2003) concordam que a Ciência da Informação é um campo interdisciplinar do conhecimento, uma vez que abrange diferentes tipos de estudos voltados à informação e ao conhecimento. Isso ocorre porque são vários os fenômenos relacionados à informação, ao conhecimento e contextos sociais.

Atualmente observa-se o surgimento de várias ciências interdisciplinares, reflexo de novas interações e interlocuções disciplinares que visam atender as demandas sociais, fator determinante para a construção de conhecimento em uma sociedade pós-moderna.

Considerando-se a Ciência da Informação uma Ciência interdisciplinar, evidenciam-se vários estudos com essa característica, como é o caso da competência em informação que, pode estar presente em múltiplos contextos: político, tecnológico, educacional, organizacional, entre outros.

Uma sociedade competente em informação é capaz de exercer plenamente sua cidadania, ou seja, os indivíduos têm a capacidade de distinguir a veracidade das informações em qualquer âmbito, conseguem reconhecer e usar fontes de informação adequadas e percebem a contrainformação.

As tecnologias de informação e comunicação são utilizadas tanto para o exercício profissional, quanto educacional e social. Nessa perspectiva, não saber utilizar os recursos tecnológicos disponíveis e acessíveis, se constitui em um fator de exclusão social. Entretanto, o indivíduo precisa ir além da possibilidade de acesso, porquanto também precisa ter competências para saber analisar e usar as informações de maneira crítica e analítica. No que tange as competências em informação, o indivíduo primeiramente deve ser capaz de diagnosticar suas próprias necessidades informacionais, saber o que, como e onde buscar as informações que podem atender as necessidades anteriormente percebidas.

Nessa perspectiva, evidencia-se a importância dos estudos voltados para a competência em informação. O papel das bibliotecas escolares nesse contexto é essencial, uma vez que a parceria e a colaboração entre o bibliotecário e o professor são determinantes para gerar adultos competentes em informação.

No contexto profissional isso não é diferente, uma vez que é fundamental que os sujeitos organizacionais saibam converter o conhecimento tácito [conhecimento - individual] em conhecimento explícito [informação - coletivo], bem como tenha uma atitude voltada à aprendizagem ao longo da vida, o que propiciará novas competências para suas atividades e tarefas profissionais. Além disso, destaca-se que a informação e o conhecimento, elementos 
essenciais de qualquer ambiente organizacional, são a matéria prima para a tomada de decisão, assim, os sujeitos organizacionais devem desenvolver competências em informação voltadas à busca, acesso e análise das informações selecionadas.

Hatschbatch e Olinto (2008, p.21) explicam que:

A necessidade do desenvolvimento de habilidades para o melhor uso e proveito da informação, nos mais diversos contextos, já não é novidade para ninguém na atualidade. Consequentemente, o interesse e a importância da Competência em Informação (Information Literacy) estão ultrapassando as fronteiras da Ciência da Informação e da Biblioteconomia, berço e terreno fértil dessa temática, particularmente no que diz respeito ao comportamento do usuário no processo de busca da informação (information-seeking behavior). A Competência em Informação já tem luz própria, como área de estudos na Ciência da Informação, com bastante autonomia, apesar de sua grande interface com outras áreas do conhecimento, entre as quais podemos mencionar a educação, as ciências sociais, a psicologia cognitiva, a comunicação, o marketing, o direito e a informática. Com certeza, este avanço é resultado das demandas da 'Sociedade da Informação', que também proporcionou novas bases conceituais, estruturas físicas e virtuais e tecnologias para o aprendizado e a aquisição de conhecimento, em sentido amplo.

De maneira geral a competência em informação esta intrinsecamente relacionada à aprendizagem, fator este de preocupação direta ou indireta das escolas de ensino fundamental e médio, bem como das universidades e, portanto, das bibliotecas escolares e universitárias. Nesse contexto, este artigo apresenta uma reflexão sobre a inter-relação da competência em informação com outras áreas do conhecimento, visando enfocar a interdisciplinaridade inerente à competência em informação, em especial com os contextos educacional, tecnológico, político e organizacional. Este artigo também destaca a complexidade da sociedade contemporânea, relacionando-a aos estudos sobre competência em informação. Morin (2007, p.102) evidencia que:

O pensamento complexo comporta e desenvolve diferentes tipos ou modos de inteligência, mas os supera pela importância de seu componente reflexivo e pela sua aptidão organizadora e criadora. A inteligência resolve problemas, mas põe outros mais profundos, gerais, sem solução [...].

Ressalta-se que desenvolver a visão ampliada sobre determinado problema é essencial para compreendê-lo em sua totalidade. Nessa direção, este artigo busca investigar os principais contextos da competência em informação. 


\section{Competência em Informação}

O bibliotecário Paul Zurkowski cunhou o termo 'Information Literacy' que, aparece no relatório The information service environment relationships and priorities, publicado em 1974 (DUDZIAK, 2003).

O termo 'information literacy' não foi traduzido uniformemente em outros países, fator que dificultou a recuperação de pesquisas sobre a referida temática. Em inglês, conforme supracitado o termo adotado foi 'information literacy', em francês adotou-se 'maîtrisse d'information', em espanhol pode-se encontrar os termos 'alfabetización informacional', 'alfabetización en información', 'competencia informacional' e 'Desarrollo de Habilidades Informativas' (DHI) no México (HATSCHBACH; OLINTO, 2008).

Em Portugal pode-se encontrar na literatura os termos 'literácia informacional', 'literácia da informação' e 'competências da informação'. No Brasil se observa os seguintes termos: 'alfabetização informacional', 'alfabetização em informação', 'competência informacional' e 'competência em informação' (HATSCHBACH; OLINTO, 2008). Recentemente, em 2014 o relatório anual da Organização das Nações Unidas para a Educação, a Ciência e a Cultura (UNESCO), 'Overview of Information Literacy Resource Worldwide', de autoria de Horton Júnior, valida o termo 'competência em informação' para uso no Brasil.

No final do ano de 1990 houve um aumento considerável sobre os estudos voltados à competência em informação nos países ibero-americanos, principalmente no âmbito da América Latina.

Belluzzo (2008, p.13) explica que o termo competência em informação pode ser compreendido sob várias concepções, bem como é necessário compreendê-lo sob duas dimensões:

[...] a primeira, um domínio de saberes e habilidades de diversas naturezas que permitem a intervenção prática na realidade e, a segunda, uma visão crítica do alcance das ações e o compromisso com as necessidades mais concretas que emergem e caracterizam o atual contexto social [...].

Para Einsenberg (2008) competência em informação se constitui nas capacidades que possibilitam a busca, a avaliação, o uso, bem como a filtragem de informação.

A definição sobre competência em informação, segundo Vitorino e Piantola (2011), enfoca aspectos objetivos e subjetivos, cujo enfoque pode ser individual ou coletivo, ou seja, são quatro dimensões relacionadas à informação. O aspecto objetivo está diretamente relacionado às competências voltadas ao uso das tecnologias de informação e comunicação, por outro lado o aspecto subjetivo diz respeito à experiência pessoal de cada indivíduo. 0 RICI: R.Ibero-amer. Ci. Inf., ISSN 1983-5213, Brasília, v. 9, n. 1, p. 124-142, jan./jun.2016. 
enfoque individual se relaciona com a conduta ética que o sujeito possui ao fazer o uso das informações disponíveis e, por fim, o enfoque coletivo está relacionado à capacidade de exercer a cidadania (Quadro 1).

Quadro 1: Dimensões da competência em informação.

\begin{tabular}{|c|c|c|c|}
\hline Dimensão Técnica & Dimensão Estética & Dimensão Ética & Dimensão Política \\
\hline $\begin{array}{l}\text { Meio de ação no } \\
\text { contexto da } \\
\text { informação. } \\
\text { Consiste nas } \\
\text { habilidades adquiridas } \\
\text { para encontrar, avaliar } \\
\text { e usar a informação } \\
\text { de que precisamos. } \\
\text { Ligada à ideia de que } \\
\text { o indivíduo é aquele } \\
\text { capaz de acessar com } \\
\text { sucesso e dominar as } \\
\text { novas tecnologias. }\end{array}$ & $\begin{array}{l}\text { Criatividade sensível. } \\
\text { Capacidade de } \\
\text { compreender, } \\
\text { relacionar, ordenar, } \\
\text { configurar e } \\
\text { ressignificar a } \\
\text { informação. } \\
\text { Experiência interior, } \\
\text { individual e única do } \\
\text { sujeito no lidar com os } \\
\text { conteúdos de } \\
\text { informação e sua } \\
\text { maneira de expressá-la } \\
\text { e agir sobre ela no } \\
\text { âmbito coletivo. }\end{array}$ & $\begin{array}{l}\text { Uso responsável da } \\
\text { informação. } \\
\text { Visa à realização do } \\
\text { bem comum. } \\
\text { Relaciona-se a } \\
\text { questões de } \\
\text { apropriação e uso da } \\
\text { informação, tais como } \\
\text { propriedade } \\
\text { intelectual, direitos } \\
\text { autorais, acesso à } \\
\text { informação e } \\
\text { preservação da } \\
\text { memória do mundo. }\end{array}$ & $\begin{array}{l}\text { Exercício da cidadania. } \\
\text { Participação dos } \\
\text { indivíduos nas decisões } \\
\text { e nas transformações } \\
\text { referentes à vida social. } \\
\text { Capacidade de ver além } \\
\text { da superfície do } \\
\text { discurso. } \\
\text { Considera que a } \\
\text { informação é produzida } \\
\text { a partir de (e em) um } \\
\text { contexto específico. }\end{array}$ \\
\hline
\end{tabular}

Fonte: Vitorino e Piantola - 2011 - p.109.

As dimensões supracitadas demostram que a competência em informação esta presente em diferentes áreas do conhecimento, conforme apresentado no Quadro 1. Nessa perspectiva, conforme mencionado anteriormente o presente artigo aborda a competência em informação relacionadas aos seguintes contextos: educacional, tecnológico, político e organizacional.

Vale lembrar que a competência em informação não possui uma única definição para o termo, entretanto, o conceito de competência em informação aparece com o advento da Sociedade da Informação e foi utilizada como uma atividade voltada ao público usuário de bibliotecas (DUDZIAK, 2008).

\subsection{Contexto Político}

No contexto político a competência em informação é incentivada, por meio das políticas públicas, programas e projetos governamentais que, incentivam o aprendizado tecnológico, a leitura, a formação para o exercício da cidadania, ou seja, iniciativas governamentais ou que possuem apoio governamental. De uma maneira mais ampla, as 
iniciativas governamentais podem modificar o conhecimento dos cidadãos, tornando-os mais críticos e cientes de seus direitos.

Segundo Bradley (2013), a quantidade de políticas voltadas à competência em informação é pequena, assim como se verifica que há poucas pesquisas que avaliam o impacto da competência em informação nas políticas públicas, uma vez que é difícil sistematizar dados e informações de iniciativas públicas por sua abrangência.

A Australian Library and Information Associations (ALIA) em sua declaração sobre competência em informação, parte do seguinte princípio:

A cultura nacional e global próspera e a economia e democracia avançadas necessitam de pessoas competentes para buscar, avaliar, usar e gerar informação de modo eficaz, visando atingir seus objetivos pessoais, sociais, profissionais e educacionais (ALIA apud BRADLEY, 2013, p.3, tradução nossa).

Nos Estados Unidos a American Library Association (ALA), por meio de sua subdivisão Association of College and Research Libraries (ACRL), apresenta diferentes objetivos voltados à competência em informação, entre eles, elaborar programas, estratégias de incentivo, normas, procedimentos, padrões, indicadores e ferramentas aplicadas ao contexto das bibliotecas. Nessa perspectiva, definiu algumas políticas relacionadas aos contextos tecnológico, educacional e político (ACRL, 2000).

No Brasil, o governo federal lançou o programa de incentivo à leitura, denominado "Leia Mais, Seja Mais", cuja meta é estimular a leitura entre famílias de baixa renda, que concentram cerca de $40 \%$ da população de não leitores ${ }^{1}$. A reflexão que se faz, refere-se ao seguinte questionamento: como um indivíduo que não é competente em informação, poderá realmente usufruir desse programa de incentivo à leitura, se não possuir condições para se apropriar, analisar e refletir sobre o que leu? A análise e a reflexão ocorrem por meio de modelos mentais que, por sua vez, necessitam de condições cognitivas que propiciem essa elucubração e, posterior compreensão. Além desse aspecto, o indivíduo deve possuir habilidades para acessar, buscar, selecionar e usar informações.

A Lei de Acesso a Informação (LAI), Lei no 12.527 de 18 de novembro de 2011, promulgada no dia 16 de maio de 2012, propicia ao cidadão brasileiro o acesso às informações governamentais, incentivando a transparência da administração pública. $O$ cidadão tem direito a solicitar informações que desejar, visando sua compreensão de aspectos legais, financeiros,

1 Portal Brasil. Disponível em: <http://www.brasil.gov.br/cultura/2012/08/programa-de-incentivo-a-leitura-leiamais-seja-mais-e-lancando>. Acesso em: 18 fev. 2015. 
políticos, econômicos, entre outros. Até o momento foram aproximadamente 132 mil pedidos de acesso a distintas informações, dos quais 128 mil $(96,7 \%)$ foram atendidos total ou parcialmente ${ }^{2}$. Neste caso, a reflexão que se faz é a seguinte: como um indivíduo que não é competente em informação, saberá realmente sobre seus direitos de acesso à própria informação e às informações governamentais, em nível federal, estadual e municipal, no intuito de conhecer de que maneira os impostos estão sendo aplicados, ou de que modo os direitos dos cidadãos de sua comunidade estão sendo atendidos?

Outra iniciativa brasileira refere-se ao Programa de Inclusão Digital do Ministério da Ciência, Tecnologia e Inovação (MCTI) que, visa proporcionar à população menos favorecida o acesso às tecnologias de informação e comunicação, capacitando cidadãos para atuarem no mercado de trabalho, e em práticas relacionadas à informática. Este Programa também se relaciona com o Programa Computador para Todos. A reflexão que se faz, refere-se a um aspecto essencial: como um indivíduo que não é competente em informação, terá realmente condições para se apropriar desses conteúdos formadores para sua atuação no mercado de trabalho?

Nos três casos supracitados a competência em informação é fundamental, por essa razão, o governo federal deve apoiar iniciativas voltadas à competência em informação buscando sua efetividade no contexto nacional.

Algumas parcerias entre órgãos nacionais ocorreram com o intuito de fortalecer as discussões e promover ações voltadas à competência em informação, entre elas a parceria entre a Universidade Estadual Paulista (Unesp), a Universidade de Brasília (UnB), o Instituto Brasileiro de Informação em Ciência e Tecnologia (IBICT) e a Federação Brasileira de Associações de Bibliotecários, Cientistas da Informação e Instituições (FEBAB), cuja parceria resultou no Seminário de Competência em Informação: cenários e tendências que aconteceu em sua primeira edição, concomitantemente ao XXIV Congresso Brasileiro de Biblioteconomia, Documentação e Ciência da Informação (CBBD), realizado em 2011, na cidade de Maceió, Alagoas. Duas outras edições do Seminário ocorreram, sendo a segunda na cidade de Florianópolis, concomitantemente ao XXV CBBD, e a terceira na Universidade Estadual Paulista (Unesp), na cidade de Marília, São Paulo. O objetivo do evento é debater e propor políticas voltadas à competência em informação a serem implementadas em diferentes contextos.

\footnotetext{
2 Portal Brasil. Disponível em: <http://www.brasil.gov.br/governo/2013/11/balanco-positivo-da-lei-de-acesso-ainformacao-e-positivo>. Acesso em: 18 fev. 2015. 
Esse tipo de iniciativa é relevante porquanto dissemina a relevância da competência em informação para a sociedade brasileira. Além disso, a competência em informação está presente no cenário político, uma vez que é alvo de programas governamentais, tanto em países desenvolvidos quanto em países em desenvolvimento.

\subsection{Contexto Tecnológico}

Com o advento das tecnologias de informação e comunicação há sempre a preocupação no que tange ao uso de tais recursos. O microcomputador, por exemplo, foi distribuído em várias escolas brasileiras, mas não foram inseridos no cotidiano das escolas, porque os professores não eram competentes em informação para usar os recursos eficientemente.

Cruz (1997, p. 160) conceitua 'tecnologias de informação e comunicação' como um “[...] conjunto de dispositivos individuais, como hardware, e software, telecomunicações ou qualquer outra tecnologia que faça parte ou gere tratamento da informação, ou ainda, que a contenha".

Segundo Duguid e Brown (2008) há um relacionamento complexo entre as tecnologias de informação e comunicação e as organizações, os referidos autores mencionam defendem que as TIC superam as instituições tradicionais e fornecem poder simplificado às pessoas. Nesse sentido, as TIC são recursos que podem ser utilizados por indivíduos competentes em informação, ou seja, o indivíduo se torna o agente principal no uso das tecnologias.

As TIC se constituem em objeto de estudo e discussão de distintos governos, cujos resultados são publicados em documentos denominados de 'livro branco' e/ou 'livro verde' ${ }^{3}$ etc., comprometendo-se a adotar medidas para a implantação das TIC e sua democratização à sociedade. No Brasil, apenas no Ano de 2000 , os resultados dos estudos e discussões realizados pelo Grupo de Implantação do Programa Sociedade da Informação (SoCinfo), vinculado ao Ministério da Ciência e Tecnologia foi publicado.

No livro 'Sociedade da Informação no Brasil - Livro Verde' verifica-se que há maior ênfase à infraestrutura para acesso à rede Internet, cabeamento, equipamentos (microcomputadores), capacidade de transmissão, entre outros elementos. No entanto, de nada vale uma infraestrutura adequada, se não há primeiramente conteúdos informacionais de interesse da sociedade, e em segundo lugar se não há indivíduos competentes em

\footnotetext{
${ }^{3}$ Fonte: Ministério da Ciência, Tecnologia e Inovação. Disponível em: <http://www.mct.gov.br/index.php/content/view/18878.html>. 
informação para acessá-las, compreendê-las e usá-las. Nessa perspectiva, o Livro Verde deveria enfatizar mais o desenvolvimento de conteúdos informacionais, bem como $o$ desenvolvimento de competências em informação para que estudantes, cidadãos, enfim a sociedade como um todo pudesse de fato usufruir dos recursos tecnológicos que caracterizam a denominada Sociedade da Informação.

De acordo com Lecardelli e Prado (2006, p.25):

A Sociedade da Informação com seus avanços tecnológicos em diversas áreas, principalmente, nas áreas da informática e na das telecomunicações, trouxe um volume cada vez maior de informações que possibilitaram acesso rápido para navegar no ciberespaço e transitar nos mais diferentes tipos de informações.

Ressalta-se que a infraestrutura de acesso e distribuição é fundamental, mas os indivíduos necessitam saber acessar, buscar, selecionar e usar as informações contidas na rede, em bancos e bases de dados, de modo a amenizar ou solucionar problemas ou, ainda, tomar decisões.

Outro aspecto que pode ser mencionado no que tange às tecnologias de informação e comunicação refere-se à errônea compreensão de que a tecnologia em si basta para a realização de atividades e tarefas de distintas naturezas, assim, surgem altas expectativas, levando as pessoas a crerem que a tecnologia substitui as competências humanas (DAVENPORT; PRUSAK, 2003).

Por outro lado, verifica-se o avanço da pesquisa e desenvolvimento voltado à inteligência artificial, agentes inteligentes e redes neurais, contudo, o desenvolvimento da competência em informação nos indivíduos é essencial até para que possam atuar eficientemente com esses novos recursos tecnológicos.

\subsection{Contexto Educacional}

As bibliotecas se tornaram mais visíveis a partir do surgimento dos serviços de referência, bem como a partir de ações voltadas à educação de usuários no uso das fontes, produtos e serviços informacionais.

As bibliotecas escolares foram motivadas pelas Teorias da Educação, priorizando novos métodos de aprendizagem focados no aluno, em substituição ao antigo método de ensino centrado no professor. Nesse contexto, os bibliotecários são vistos como profissionais que podem contribuir com as novas estratégias didáticas (CAMPELLO, 2003).

Assim, em 1984, a American Library Association (ALA) publicou um documento denominado 'Libraries and the learning society: Papers in response to a nation at risk', cujo 
objetivo era demonstrar a atuação da biblioteca escolar voltada para ao 'aprender a aprender'. Além disso, objetivou estimular competências e habilidades para acessar, buscar e usar a informação, capacidade imprescindível para viver em uma sociedade complexa (CAMPELLO, 2003).

O livro 'Information Power: Building partnerships for learning'4 propõe várias ações para o desenvolvimento da competência em informação de alunos desde o ensino fundamental até o ensino médio. Nessa perspectiva, o referido documento define as competências em informação, tanto no âmbito teórico quanto prático, divididas em três grupos: 1. Competência em informação voltada ao manuseio da informação; 2. Competência em informação voltada à aprendizagem autônoma e independente; 3. Competência em informação voltada à responsabilidade social.

Ressalta-se que a biblioteca escolar deve ter relação direta com a escola, bem como deve se inserir em um contexto de aprendizagem ao longo da vida, admitindo-se que o trabalho integrado de professores e bibliotecários é um fator determinante para que isso ocorra eficientemente (BELLUZZO, 2008).

Quadro 2: Competência em Informação - Normas e Indicadores da ACRL.

Norma 1: $O$ aluno competente em informação determina a natureza e a extensão das informações necessárias.

Indicadores:

1. O aluno competente em informação define e articula as necessidades informacionais.

2. O aluno competente em informação identifica uma variedade de tipos e formatos de fontes potenciais de informação.

3. O aluno competente em informação considera os custos e os benefícios de adquirir as informações necessárias.

4. O aluno competente em informação reavalia a natureza e a extensão das necessidades de informação.

Norma 2: 0 aluno competente em informação acessa as informações necessárias de modo eficaz e eficiente.

Indicadores:

1. O aluno competente em informação seleciona os métodos de investigação ou sistemas de recuperação de informação mais adequados para acessar as informações necessárias.

2. O aluno competente em informação constrói e implementa estratégias de busca eficazes.

3. O aluno competente em informação recupera informações online ou in loco, usando uma variedade de métodos.

4. O aluno competente em informação refina a estratégia de busca, se necessário.

5. O aluno competente em informação extrai, registra e gerencia as informações e suas fontes.

Norma 3: 0 aluno competente em informação avalia as informações e suas fontes de modo crítico e incorpora as informações selecionadas em sua base de conhecimento e sistema de valores.

Indicadores:

${ }^{4}$ Fonte: <http://www.alastore.ala.org/detail.aspx?ID=203>. Acesso em: 18 fev. 2015.

RICI: R.Ibero-amer. Ci. Inf., ISSN 1983-5213, Brasília, v. 9, n. 1, p. 124-142, jan./jun.2016. 
1. O aluno competente em informação resume as principais ideias a serem extraídas da informação selecionada.

2. O aluno competente em informação articula e aplica critérios iniciais para avaliar tanto a informação quanto suas fontes.

3. O aluno competente em informação sintetiza as principais ideias para a construção de novos conceitos.

4. O aluno competente em informação compara novo conhecimento com conhecimentos prévios para determinar o valor agregado, contradições ou outras características relacionadas à informação.

5. O aluno competente em informação determina se o novo conhecimento tem impacto sobre o próprio sistema de valores e toma medidas para reconciliar as diferenças.

6. O aluno competente em informação valida sua compreensão e interpretação das informações, por meio de interlocuções com outros indivíduos, profissionais e/ou especialistas de áreas especializadas.

7. O aluno competente em informação determina se a estratégia de busca inicial deve ser revista.

Norma 4: 0 aluno competente em informação, individualmente ou como membro de um grupo, usa a informação de modo eficaz para cumprir um propósito específico.

Indicadores:

1. O aluno competente em informação aplica a nova informação antes da concepção e criação de um produto ou de seu desempenho profissional.

2. O aluno competente em informação revisa o processo de desenvolvimento do produto ou desempenho.

3. O aluno competente em informação comunica o produto ou o desempenho de modo eficaz aos outros.

Norma 5: 0 aluno competente em informação compreende muitas das questões econômicas, jurídicas e sociais que envolvem o acesso e uso de informações, e usa as informações de maneira ética e legal.

Indicadores:

1. O aluno competente em informação compreende muitas das questões éticas, legais e socioeconômicas que cercam a informação e as tecnologias de informação e comunicação.

2. O aluno competente em informação segue as leis, regulamentos, políticas institucionais e normas éticas relacionadas ao acesso e uso de recursos informacionais.

3. O aluno competente em informação reconhece o uso de fontes de informação para comunicar um produto ou desempenho.

Fonte: ACRL - 2000 - tradução nossa.

A competência em informação propicia aos alunos a capacidade de aprender de uma maneira mais independente, de usar recursos tecnológicos para realizar o acesso, busca de informação, obtendo informações de qualidade para seu uso/aplicação. Além disso, desenvolvem o pensamento crítico, pois selecionam fontes de informação confiáveis e filtram as que são irrelevantes para o contexto de pesquisa.

Para Belluzzo (2008), a competência em informação deve ser compreendida de modo complexo, envolvendo desde o conceito de informação até as demandas informacionais da sociedade. A educação depende em sua essência de indivíduos competentes em informação, por essa razão é importante que professores e bibliotecários interajam cada vez mais.

De acordo com Belluzzo (2008, p.13) o trabalho de professores e bibliotecários devem se basear nas seguintes ações: 
- Preparação de diretrizes básicas para iniciativas conjuntas sob o enfoque das necessidades da sociedade da informação e dos princípios da Competência em Informação, uma atividade intra-curricular.

- Definir as condições para que tais iniciativas possam ser apoiadas por políticas e pelas comunidades assistidas.

- Implementar e criar mecanismos de manutenção e avaliação das práticas pedagógicas e informacionais.

Nessa perspectiva, bibliotecários e professores necessitam desenvolver estratégias educacionais e informacionais a fim de que sejam, cada vez mais, independentes no que tange a aprendizagem, não obstante devem procurar apoios de comunidades e apoio político para o estímulo da competência em informação nas escolas. Por fim, os profissionais devem dar feedback, ou seja, avaliar as práticas educacionais e informacionais implantadas, visando melhorar continuamente os métodos de ensino e aprendizagem.

\subsection{Contexto Organizacional}

A sociedade do Século XXI é denominada de Sociedade da Informação e do Conhecimento, porquanto informação e conhecimento estão presentes em todos os aspectos da vida humana. De acordo com Miranda (2004) a construção de conhecimento aplicado à inovação se constitui em um novo desafio organizacional, portanto é essencial a autonomia, a criatividade e os saberes relacionados aos processos organizacionais que geram diferenciais competitivos.

Nessa perspectiva, a informação e o conhecimento ganham mais destaque, uma vez que o conhecimento ocorre por meio do sujeito organizacional, ou seja, o indivíduo gera conhecimento e o utiliza para realizar suas atividades, tarefas e tomada de decisão.

A competência em informação também foi percebida no contexto organizacional, pois se constitui em um fator determinante que influencia o processo decisório e, consequentemente, no desempenho da organização. A partir do advento da globalização e internacionalização da economia, o mundo empresarial se tornou altamente competitivo.

Nesse contexto, destaca-se a criação do 'Big 6', criado por Einsenberg na Década de 90, cujo modelo enfoca a competência em informação, descrito como: meta cognitivo, não linear e prescritivo. O 'Big 6' pode ser aplicado em três contextos distintos: no processamento da informação, no uso da tecnologia para a solução de problemas informacionais e nas necessidades reais dos indivíduos. 
Quadro 3: Modelo Big 6 - Einsenberg.

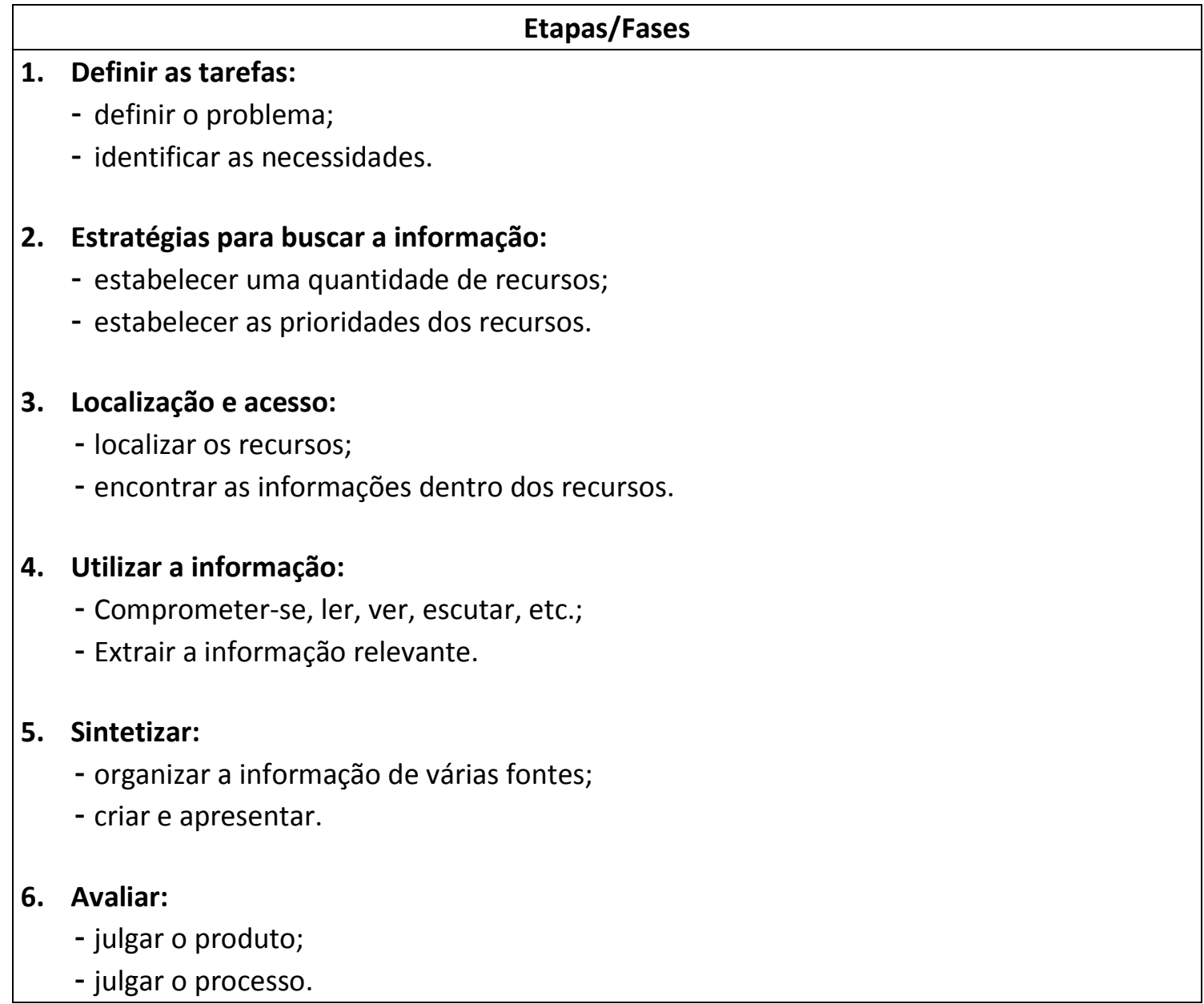
Fonte: Calderón Rehecho - 2010 - p.38 - tradução nossa.

A informação e o conhecimento propiciam à empresa lidar com os eventos cotidianos, mas também com os eventos inesperados, e essa é a diferença entre as organizações que gerenciam informação e conhecimento eficientemente com as que não o fazem. Destaca-se também a importância da comunicação organizacional, pois é por meio dos fluxos comunicacionais e informacionais que a informação e o conhecimento circulam no ambiente organizacional. Dessa maneira, os ambientes de aprendizagem se formam integrando, informação, conhecimento, sujeitos organizacionais e objetivos e metas que necessitam ser atingidos. Nesse contexto dinâmico, a competência em informação é essencial e, por essa razão, precisa ser desenvolvida organizacionalmente.

Einsenberg, Lowe e Spitzer (2004) afirmam que os líderes organizacionais têm interesse em ampliar e melhorar as competências e habilidades dos sujeitos organizacionais. Assim, há mais investimento por parte das organizações, no que tange a propiciar cursos de capacitação, apoiar a educação continuada, bem como implantar universidades corporativas em sua estrutura organizacional. 
De modo geral, existem três tipos de competências necessárias ao ambiente organizacional:

1) Competências Administrativas: são relacionadas aos processos, atividades e tarefas que o sujeito organizacional desempenha no seu dia a dia;

2) Competências Humanas: são voltadas ao relacionamento humano e à gestão de pessoas: delegação de tarefas; motivação; liderança; trabalho em equipe etc.;

3) Competências em Informação: são relacionadas ao manejo da informação envolvendo: diagnosticar as próprias necessidades informacionais; conhecer as fontes de informação adequadas; saber elaborar estratégias de busca; saber realizar a busca nos recursos tecnológicos existentes, saber filtrar e selecionar as informações relevantes; usar/aplicar corretamente as informações.

De acordo com Valentim (2010), todas as atividades organizacionais sofrem influencias diretas ou indiretas da informação e do conhecimento, assim, saber lidar com tais recursos propicia à organização gerar diferenciais competitivos que, por sua vez, a mantém no mercado em que atua.

O U. S. Department of Labor, mais especificamente a Secretary's Commisson on Achieving Necessary Skills (SCANS) $^{5}$ indica 5 (cinco) competências necessárias para os indivíduos atuarem em organizações: 1. Recursos: identifica, organiza, planeja e aloca recursos; 2 . Interpessoal: trabalha com os outros; 3 . Informação: adquire e usa informações; 4. Sistemas: compreende inter-relações complexas; e 5. Tecnologia: trabalha com vários tipos de tecnologias (Quadro 4).

Quadro 4: Competências e habilidades necessárias ao trabalhador.

\section{Know-How para Atuar em Organizações}

O know-how identificado pela SCANS é composto de cinco competências e três habilidades necessárias para o desempenho de um sujeito organizacional.

Trabalhadores competentes e eficazes podem usar produtivamente:

- Recursos - alocação de tempo, dinheiro, materiais, espaço e pessoal;

- Habilidades interpessoais - realizar trabalho em equipe, ensinar os outros, servir os clientes, conduzir, negociar, trabalhar bem com pessoas de diferentes origens culturais;

- Informação - aquisição e avaliação de dados, organização e manutenção de arquivos, interpretação

\footnotetext{
${ }^{5}$ Secretary's Commisson on Achieving Necessary Skills (SCANS) é uma associação americana formada para assessorar o Governo daquele País, a respeito das competências e habilidades necessárias aos indivíduos, para serem empregados no mercado de trabalho. Disponível em: <http://wdr.doleta.gov/SCANS/whatwork/>. Acesso em: 18 fev. 2015.
} 
e comunicação, uso de computadores para processar informações;

- Sistemas - compreendendo os sistemas: sociais, organizacionais e tecnológicos, monitoramento e correção de desempenho e projeção e/ou melhoria de sistemas;

- Tecnologia - seleção de equipamentos e ferramentas, aplicação de tecnologia para tarefas específicas, manutenção de tecnologias e solução de problemas.

Habilidades/qualidades requeridas:

- Habilidades básicas: leitura, escrita, aritmética e matemática, fala e escuta;

- Habilidades de reflexão: pensar criativamente, tomar decisões, resolver problemas, ver as coisas ampliadas e aprofundadas, saber como aprender e raciocinar;

- Qualidades interpessoais: responsabilidade individual, autoestima, sociabilidade, autogestão e integridade.

Fonte: SCANS - 1991 - p. iii; - tradução nossa.

O trabalhador competente em informação está preparado para refletir criticamente sobre a solução de um problema e alcançar os objetivos organizacionais propostos, por meio do raciocínio baseado em evidencias. Para tanto, se baseia em três aspectos: no conhecimento, nas alternativas exequíveis e na avaliação de resultados anteriores (BELLUZZO, 2006).

Para utilizar eficientemente informação e conhecimento é necessário que os sujeitos organizacionais possuam competência em informação nos níveis estratégico, tático e operacional. Dessa maneira, uma organização que desenvolva princípios e valores positivos em relação à informação e ao conhecimento, estimulará naturalmente as competências em informação dos sujeitos organizacionais.

\section{Considerações Finais}

A competência em informação abrange diversos contextos por se tratar das habilidades, atitudes e comportamentos apreendidos e desenvolvidos pelos indivíduos.

No contexto político é fundamental que o cidadão saiba como buscar informação, analisá-la criticamente e usá-la para a consolidação de um país democrático. Nessa perspectiva, é fundamental saber reconhecer a contrainformação ou a desinformação publicada, principalmente, quando envolve poder político ou econômico.

No contexto tecnológico, destaca-se a importância de o indivíduo saber manejar as tecnologias de informação e comunicação. A competência em informação está associada a essa capacidade, neste caso destacam-se as habilidades para acessar, buscar, interagir e utilizar os recursos tecnológicos disponíveis.

No contexto educacional há a necessidade de se desenvolver um trabalho colaborativo/cooperativo entre o bibliotecário e o professor, visando à melhoria contínua do 
ensino-aprendizagem, estimulando a competência em informação de alunos de diferentes níveis formativos.

No contexto organizacional a competência em informação engloba as habilidades relacionadas a identificação das necessidades de informação, o uso de fontes de informação relevantes, a habilidade de selecionar a informação pertinente e usá-la de maneira a propiciar à organização diferenciais competitivos. A tomada de decisão eficaz ocorre por meio das capacidades e conhecimentos dos sujeitos organizacionais em todos os níveis hierárquicos.

A presente pesquisa apresentou alguns ambientes em que a competência em informação está presente e é essencial, demonstrando a complexidade desta temática de investigação. Morin (2007), um dos fundadores das discussões sobre o pensamento complexo, destaca que este desenvolve diferentes tipos de inteligência, portanto, uma visão mais ampla e aprofundada sobre um determinado objeto e/ou fenômeno.

A competência em informação não se reduz somente aos contextos político, tecnológico, educacional e organizacional, mas também aos contextos econômico, artístico, científico, entre outros. Nessa perspectiva, sugerem-se que outras abordagens e reflexões sobre a competência em informação sejam objeto de futuras pesquisas.

\section{Referências}

ACRL. The Association of College and Research Libraries. Literacy competency standards for higher education. Chicago: ALA, 2000.17p.

BELLUZZO, R. C. B. Como desenvolver a competência em informação (Cl): uma mediação integrada entre a biblioteca e a escola. CRB-8 Digital, São Paulo, v. 1, n. 2, p. 11-14, out. 2008. Disponível em: <http://www.revista.crb8.org.br/index.php/crb8digital/article/viewFile/25/25>. Acesso em: 18 fev. 2015.

BELLUZZO, R. C. B. O uso de mapas conceituais e mentais como tecnologia de apoio à gestão da informação e da comunicação: uma área interdisciplinar da competência em informação. Revista Brasileira de Biblioteconomia e Documentação: Nova Série, São Paulo, v. 2, n. 2, p. 87-89, dez. 2006. Disponível em: <http://rbbd.febab.org.br/rbbd/article/view/19/7>. Acesso em: 18 fev. 2015.

BORKO, H. Information Science: What is it? American Documentation, v. 19, n. 1, p. 3-5, Jan. 1968. Disponível em: <http://cdigital.uv.mx/bitstream/123456789/6699/2/Borko.pdf>. Acesso em: 18 fev. 2015.

BRADLEY, C. Information literacy policy development in Canada: Is it time? Partnership: Canadian Journal of Library and Information Practice and Research, v.8, n.2, p.1-28, 2013. Disponível em: <https://journal.lib.uoguelph.ca/index.php/perj/article/view/2489/3053\#.VOOBuebF8pk>. Acesso em: 18 fev. 2015. 
CALDERÓN REHECHO, A. Informe APEI sobre alfabetización informacional. Madrid: APEI, 2010. 107p. (Informe APEI, 5). Disponível em: <http://eprints.rclis.org/bitstream/10760/14972/1/Informeapeialfin.pdf>. Acesso em: 27 out. 2011.

CAMPELLO, B. O movimento da competência informacional: uma perspectiva para o letramento informacional. Ciência da Informação, Brasília, v. 32, n. 3, p. 28-37, set./dez. 2003. Disponível em: <http://revista.ibict.br/cienciadainformacao/index.php/ciinf/article/view/26/22>. Acesso em: 18 fev. 2015.

CHOO, C. W. A organização do conhecimento: como as organizações usam a informação para criar significado, construir conhecimento e tomar decisões. São Paulo: Editora SENAC, 2003. $425 \mathrm{p}$.

CRUZ, T. Sistemas, organização \& métodos. São Paulo: Atlas, 1997. 230p.

DAVENPORT, T. H.; PRUSAK, L. Conhecimento empresarial: como as organizações gerenciam o seu capital intelectual. Rio de Janeiro: Elsevier, 2003. 237p.

DUDZIAK, E. A. Information literacy: princípios, filosofia e prática. Ciência da Informação, Brasília, v. 32 , n. 1, p. 23-35, jan./abr. 2003. Disponível em: <http://revista.ibict.br/ciinf/index.php/ciinf/article/view/123/104>. Acesso em: 18 fev. 2015.

DUDZIAK, E. A. Os faróis da Sociedade da Informação: uma análise crítica sobre a situação da competência em informação no Brasil. Informação \& Sociedade: Estudos, João Pessoa, v. 18, n. 2, p. 41-53, maio/ago. 2008 Disponível em: <http://www.ies.ufpb.br/ojs/index.php/ies/article/view/1704/2109>. Acesso em: 18 fev. 2015.

DUGUID, P.; BROWN, J. S. Estrutura e espontaneidade: conhecimento e organização. In: FLEURY, M. T. L.; OLIVEIRA JÚNIOR, M. de M. (Orgs.). Gestão estratégica do conhecimento: integrando aprendizagem, conhecimento e competências. São Paulo: Atlas, 2008. 349p.

EINSENBERG, M. B.; LOWE, C. A.; SIPTZER, K. L. Information literacy: essential skills for the information age. 2. ed. Westport (CO): Libraries Unlimited, 2004. 408p.

EINSENBERG, M. B. Information literacy: essential skills for the information age. DESIDOC: Journal of Library and Information Technology, v. 28, n .2, p. 39-47, Mar. 2008. Disponível em: <http://studystream.org/upload/data/6/Essential\%20Skills\%20for\%20the\%20Information\%20 Age.pdf>. Acesso em: 18 fev. 2015.

HATSCHBACH, M. H. de L.; OLINTO, G. Competência em informação: caminhos percorridos e novas trilhas. Revista Brasileira de Biblioteconomia e Documentação: Nova Série, São Paulo, v. 4, n. 1, p. 20-34, jan./jun. 2008. Disponível em: <http://rbbd.febab.org.br/rbbd/article/view/64/78>. Acesso em: 18 fev. 2015.

LECARDELLI, J.; PRADO, N. S. Competência informacional no Brasil: um estudo bibliográfico no período de 2001 a 2005. Revista Brasileira de Biblioteconomia e Documentação: Nova Série, São Paulo, v. 2, $\mathrm{n}$.2, p. 21-46, dez. 2006. Disponível em: <http://rbbd.febab.org.br/rbbd/article/view/16/4>. Acesso em: 18 fev. 2015. 
MIRANDA, S. V. Identificando competências informacionais. Ciência da Informação, Brasília, v. 33, n. 2, p. 112-122, maio/ago. 2004. Disponível em: <http://revista.ibict.br/ciinf/index.php/ciinf/article/view/83/76>. Acesso em: 18 fev. 2015.

MORIN, E. O método 5: a humanidade da humanidade. 4.ed. Porto Alegre: Sulina, 2007. 309p.

SARACEVIC, T. Interdisciplinarity nature of Information Science. Ciência da Informação, Brasília, v. 24, n. 1, p. 36-41, abr. 1995. Disponível em: <http://revista.ibict.br/ciinf/index.php/ciinf/article/view/530/482>. Acesso em: 18 fev. 2015.

VITORINO, E. V.; PIANTOLA, D. Dimensões da competência informacional (2). Ciência da Informação, Brasília, v. 40, n. 1, p. 99-110, jan./abr. 2011. Disponível em: <http://revista.ibict.br/ciinf/index.php/ciinf/article/view/1918/1397>. Acesso em: 18 fev. 2015.

Recebido/Recibido/Received: 2015-05-26 Aceitado/Aceptado/Accepted: 2015-08-27 